\title{
The Uniform Cortex Sign: A Diagnostic Sign of Diffuse Cortical Injury on MR Imaging of the Brain at $1.5 \mathrm{~T}$
}

\author{
Andrew Leung, Apurva Patel, Basem Bahakeem, David Pelz, Donald Lee, \\ Manas Sharma
}

\begin{abstract}
Background: To introduce the "uniform cortex sign" (UCS) and evaluate its performance as a diagnostic test for the presence of diffuse cortical injury (DCI). Methods: The study was approved by our institutional review board. Three experienced neuroradiologists were given a tutorial on the UCS. They were subsequently presented with 14 cases ( 7 control patients and 7 DCI patients with the UCS) in random order and asked to determine whether the UCS was present. Each case consisted of selected DWI, T2-weighted, and FLAIR images from unenhanced 1.5T MRI examinations. A consensus result for each case was determined by unanimity or majority rule. Results: All control patients were correctly identified as normal by all neuroradiologists (7/7). The UCS was correctly identified in $86 \%$ of DCI patients (6/7). UCS interrater agreement was high (multirater K $=0.81$ ). Conclusions: This small study shows that the UCS can identify DCI, especially in patients with hypoxic-ischemic encephalopathy. The UCS can be subtle, hence the reader must be vigilant for this finding. The accuracy of the UCS may depend on the extent of cortical injury and time between injury and MRI. Also, a UCS may be reversible, as in our case of viral meningoencephalitis.
\end{abstract}

RÉSUMÉ: Contexte: Le but de l'étude était de présenter le « signe du cortex uniforme » (SCU) et d'évaluer son efficacité comme test diagnostic de la présence d'une atteinte corticale diffuse (ACD). Méthodologie: Cette étude a été approuvée par notre comité d'examen institutionnel. Trois neuroradiologues d'expérience ont reçu une formation sur le SCU. Quatorze cas (7 patients-témoins et 7 patients présentant une ACD avec SCU leur ont ensuite été présentés dans un ordre aléatoire. On leur a demandé de déterminer si un SCU était présent. Pour chaque cas, le neuroradiologue avait accès à des images IRM pondérées en diffusion, pondérées T2 et en séquence FLAIR d'examens par IRM à 1.5T non rehaussée. Le consensus était déterminé pour chaque cas par une décision unanime ou majoritaire. Résultats: Tous les patients-témoins ont été identifiés correctement comme étant normaux par tous les neuroradiologues (7/7). Le SCU a été identifié correctement chez $86 \%$ des patients présentant une ACD (6/7). L'accord inter-neuroradiologue était élevé $(K=0,81)$. Conclusions: Cette petite étude démontre que le SCU peut identifier l'ACD, particulièrement chez les patients atteints d'encéphalopathie hypoxique-ischémique. Le SCU peut être subtil et le lecteur doit le rechercher systématiquement. La manifestation du SCU peut dépendre de l'étendue de l'atteinte corticale et du temps écoulé entre le traumatisme et l'IRM. De plus, le SCU peut être réversible, comme ce fut le cas chez notre cas de méningoencéphalite virale.

Keywords: Critical care, Ischemic brain injury, Magnetic resonance imaging

doi:10.1017/cjn.2017.223

Can J Neurol Sci. 2017; 44: 664-669

\section{INTRODUCTION}

Identification of the central sulcus (CS) on MR imaging is important for accurate anatomic localization of motor and sensory cortices, especially in patients undergoing surgical treatment. Several topographic features can be utilized on CT and MR imaging to localize the CS. ${ }^{1-4}$ A less commonly known feature is the thin cortex sign (TCS). ${ }^{1,5}$ The cortical thickness of the posterior bank of the CS is among the thinnest in the brain, and the cortical thickness of the anterior bank is 1.5 to 2 times greater on T1-weighted images. TCS has been described in other studies using measurements of cortical thickness from T2-weighted MR images in patients with vasogenic edema from metastases. ${ }^{6,7}$ Low signal intensity on FLAIR images has been shown to landmark the perirolandic cortex as well. ${ }^{8}$

Diffuse cortical injury (DCI) often results from hypoxicischemic encephalopathy (HIE), most commonly from cardiac or respiratory arrest. ${ }^{9,10}$ The clinical diagnosis of HIE is primarily made by history and physical examination (including pupillary light response, corneal reflex, motor response to pain, and myoclonus status epilepticus), with imaging, EEG, and somatosensory-evoked potentials as supporting evidence. ${ }^{11}$ Previous studies ${ }^{10,12}$ have described the MRI findings in HIE, which include cortical hyperintensity on diffusion-weighted imaging (DWI), T2-weighted images, and FLAIR images.

From the Department of Medical Imaging, London Health Sciences Centre, London, Ontario, Canada (AL, AP, BB, DP, DL, MS); Department of Diagnostic Imaging, Belleville General Hospital, Belleville, Ontario, Canada (AP); Department of Medical Imaging, King Abdullah Medical City, Jeddah, Saudi Arabia (BB).

Received April 4, 2017. Final Revisions Submitted May 13, 2017. Date of ACCEPTANCE MAY 21, 2017.

Correspondence to: Andrew Leung, Department of Medical Imaging, London Health Sciences Centre, C1-649, 800 Commissioners Road East, London, Ontario N6A 5W9, Canada. Email: andrew.leung@lhsc.on.ca. 
On occasion, we have noted loss of the TCS in patients with HIE presenting to our institution, a sign we have termed the "uniform cortex sign" (UCS). Even though these patients have severe neurological compromise, these MRI findings can be difficult to detect. As the UCS has not been described previously, its effectiveness to detect DCI is unknown.

The purpose of this study is to introduce the UCS and evaluate its performance as a test for the presence of DCI.

\section{Methods}

Institutional review board approval was obtained for this retrospective study, and informed consent was waived by the IRB.

\section{Control Patients}

Some 9 control patients (CPs) were identified from the population at our institution who underwent outpatient MR screening for intracranial aneurysms because of significant family history of cerebral aneurysm between July and November of 2014 (mean age $=41$ years, age range $=13-59$ years). There were 4 males (mean age $=45$ years, age range $=13-59$ years) and 5 females (mean age $=37$ years, age range $=26-55$ years). Their MR studies were unremarkable. No patients were excluded.

\section{Diffuse Cortical Injury Patients with UCS}

A total of 8 patients had a decreased level of consciousness or were comatose at presentation and had the UCS on MR imaging at our institution between May and November of 2014 (mean age $=36$ years, age range $=12-75$ years). There were 4 males (mean age $=39$ years, age range $=16-75$ years) and 4 females (mean age $=32$ years, age range $=12-55$ years) (see Table 1$)$. All patients had diffuse cortical injury on clinical exam (as determined by either a neurologist or a critical care physician) and
MRI, and 6 patients also had confirmatory EEG abnormalities (the other 2 did not have an EEG). Some 7 patients suffered from hypoxic-ischemic encephalopathy (HIE). Of these patients, 3 had cardiopulmonary arrest, 2 had cerebral hypoperfusion from hanging, 1 had a pulseless electrical activity arrest from tricyclic antidepressant overdose, and 1 had hypoxia from drowning. Some 6 HIE patients underwent the hypothermia protocol. All 7 patients with HIE died in hospital after life support was withdrawn. No brain autopsies were performed. One patient was admitted with viral meningoencephalitis and made a full recovery.

\section{MR Imaging, Processing, ANd Review}

MR imaging was performed on 1.5T scanners (Signa HDx or Optima MR450w; GE Healthcare, Milwaukee, Wisconsin). Our MRI protocol included axial DWI (10000/114 [TR/TE]; 5-mm section thickness; $b=1000 \mathrm{~s} / \mathrm{mm}^{2}$; matrix $\left.128 \times 192\right)$; axial T2 FSE (3500/85 [TR/TE]; 2-mm section thickness; matrix $256 \times 256)$; sagittal FLAIR CUBE with axial and coronal reformats $(\mathrm{TR} / \mathrm{TE}=6000 / 130$; auto $\mathrm{TI}$; section thickness $=1.8 \mathrm{~mm}$; matrix $=224 \times 224)$. The FOV was $24 \times 24 \mathrm{~cm}$ for all sequences.

Using selected MR images from two CPs (TCS 8 and 9) and one DCI patient (UCS 8), three fellowship-trained neuroradiologists with 30, 25, and 8 years experience (DP, DL, MS) were given a tutorial to identify the TCS and UCS by the principal investigator ( $\mathrm{AL}$ ) and study coordinators (AP, BB). The selected images consisted of two images from axial DWI, axial T2, and axial FLAIR sequences in addition to a single paramedian sagittal FLAIR image and seven contiguous coronal FLAIR images. The DCI tutorial patient did not have an axial T2 sequence performed. Effort was made to exclude slices that included other signs associated with the central sulcus or other abnormalities in the DCI patients. On axial and sagittal images of the CPs, the readers were

Table 1: Uniform cortex sign (UCS) in patients with diffuse cortical injury

\begin{tabular}{|c|c|c|c|c|c|c|c|c|c|}
\hline \multirow[b]{2}{*}{ Patient } & \multirow[b]{2}{*}{$\begin{array}{l}\text { Age/ } \\
\text { gender }\end{array}$} & \multirow[b]{2}{*}{$\begin{array}{l}\text { Etiology of } \\
\text { injury }\end{array}$} & \multirow[b]{2}{*}{$\begin{array}{l}\text { Hypo- } \\
\text { thermia } \\
\text { protocol }\end{array}$} & \multirow[b]{2}{*}{ EEG time after injury and interpretation } & \multirow[b]{2}{*}{$\begin{array}{l}\text { Time of } \\
\text { MRI } \\
\text { after } \\
\text { injury }\end{array}$} & \multirow[b]{2}{*}{$\begin{array}{l}\text { Outcome after } \\
\text { life support } \\
\text { withdrawn }\end{array}$} & \multicolumn{3}{|c|}{ UCS correctly identified } \\
\hline & & & & & & & $\underset{1}{\text { Reader }}$ & $\underset{2}{\text { Reader }}$ & $\underset{\mathbf{3}}{\text { Reader }}$ \\
\hline UCS 1 & $12 / \mathrm{F}$ & $\begin{array}{l}\text { Hanging with } \\
\text { cerebral } \\
\text { hypoperfusion }\end{array}$ & Yes & 2 days; severe anoxic brain injury & 2 days & Died & $\mathrm{Y}$ & $\mathrm{Y}$ & $\mathrm{Y}$ \\
\hline UCS 2 & $16 / \mathrm{M}$ & $\begin{array}{l}\text { viral meningo- } \\
\text { encephalitis }\end{array}$ & No & $\begin{array}{l}2 \text { days; severe generalized encephalopathy } \\
\text { but reactivity to stimuli favors a better } \\
\text { prognosis }\end{array}$ & 7 days & Full recovery & $\mathrm{N}$ & $\mathrm{N}$ & $\mathrm{N}$ \\
\hline UCS 3 & $55 / \mathrm{F}$ & $\begin{array}{l}\text { Respiratory } \\
\text { failure from } \\
\text { COPD and } \\
\text { pneumonia }\end{array}$ & Yes & $\begin{array}{l}4 \text { days; severe generalized encephalopathy } \\
\text { consistent with a post-anoxic state }\end{array}$ & 5 days & Died & $\mathrm{Y}$ & $\mathrm{Y}$ & $\mathrm{Y}$ \\
\hline UCS 4 & $75 / \mathrm{M}$ & Cardiac arrest & Yes & $\begin{array}{l}7 \text { days; severe generalized cortical damage, } \\
\text { likely ischemic in origin }\end{array}$ & 6 days & Died & $\mathrm{Y}$ & $\mathrm{N}$ & $\mathrm{Y}$ \\
\hline UCS 5 & $14 / \mathrm{F}$ & $\begin{array}{l}\text { Hanging with } \\
\text { cerebral } \\
\text { hypoperfusion }\end{array}$ & No & NA & 1 day & Died & $\mathrm{Y}$ & $\mathrm{Y}$ & $\mathrm{Y}$ \\
\hline UCS 6 & $49 / \mathrm{F}$ & Cardiac arrest & Yes & $\begin{array}{l}2 \text { days; lack of background activity and } \\
\text { failure of any EEG response to afferent } \\
\text { stimuli indicate a poor prognosis }\end{array}$ & 4 days & Died & $\mathrm{Y}$ & $\mathrm{Y}$ & $\mathrm{Y}$ \\
\hline UCS 7 & $18 / \mathrm{M}$ & $\begin{array}{l}\text { PEA arrest from } \\
\text { TCA overdose }\end{array}$ & Yes & 6 days; global irreversible cortical death & 6 days & Died & $\mathrm{Y}$ & $\mathrm{Y}$ & $\mathrm{Y}$ \\
\hline UCS 8 (tutorial) & $48 / \mathrm{M}$ & Drowning & Yes & NA & 2 days & Died & NA & NA & NA \\
\hline
\end{tabular}




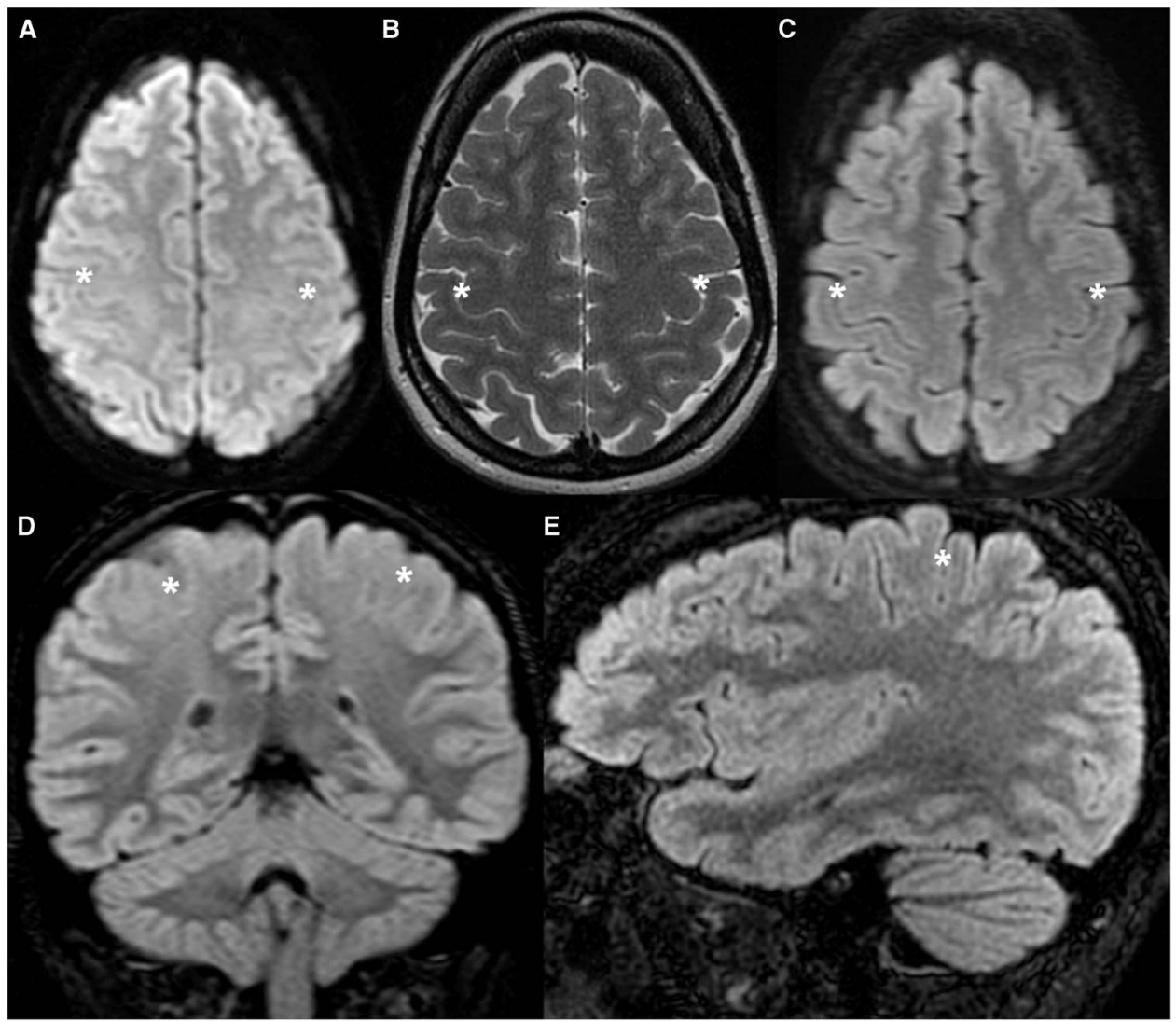

Figure 1: Healthy tutorial control patient (TCS 9) demonstrating the normal appearance of the cortex along the posterior bank of the CS. (A) Axial DWI. (B) Axial T2-weighted image. $(C, D, E)$ Axial, coronal and sagittal FLAIR images. The cortex along the posterior bank of the CS (asterisk) is thinner than the anterior bank of the CS and the posterior banks of adjacent sulci in the axial and sagittal planes, and thinner than the temporal cortex in the coronal plane.

shown that the cortical thickness of the posterior bank of the CS was thinner than the anterior bank of the CS and the posterior banks of adjacent sulci (Figure 1). Either criterion could be used to identify the CS. On coronal images of the CPs, the CS could be identified by comparing the thickness of the paramedian cortex to that of the temporal cortex. Conversely, these differences in cortical thickness are not apparent with DCI, as the cortical thickness is relatively uniform (Figure 2). The tutorial patients were not used in the subsequent testing.

The remaining seven DCI (UCS) and seven control (TCS) cases were used to determine the utility of the UCS in identifying patients with diffuse cortical swelling. The cases were presented in random order. Each radiologist was independently shown cases of selected images (similar slices as tutorial images) on a PACS workstation (GE Centricity, Milwaukee, Wisconsin). The reader was allowed to window the images according to their preference. No patient information was visible on these images. No measurements were made. In one control patient, no axial FLAIR images were available.

The presence of the TCS or UCS was determined in binary fashion. The data for the three readers were grouped for each patient, and a consensus response was derived based on unanimity or majority rule.

An online kappa calculator was used to measure $\kappa$ statistics for interrater reliability. ${ }^{13}$

\section{ReSUltS}

The results of the study are tabulated in Table 1 . In all CPs, the cortex of the posterior bank of the CS was thinner than the anterior bank of the CS or the posterior banks of other adjacent sulci (Figure 3). Conversely, in 6 of the 7 patients with DCI, the cortex of the posterior bank was thicker than normal and relatively uniform compared to the anterior bank as well as adjacent gyri (Figure 4).

\section{Performance of the UCS as a Test}

The accuracy of the presence of a UCS as a test for DCI was $86 \%$. There was a high rate of agreement between the readers (multirater $\kappa=0.81$ ). Figure 4 shows representative axial T2 images from study patients with DCI. The UCS was correctly identified in six of the seven patients with diffuse cortical injury (unanimously in five patients and by a majority [two of three] in one). None of the readers identified the UCS in UCS 2 (who presented with viral meningoencephalitis and subsequently made a full recovery). Reader 2 also thought that UCS 4 (who had suffered from cardiac arrest) was normal.

\section{Discussion}

It has been known for over 100 years that the cerebral cortex is not uniform. The cortex of the posterior bank of the central sulcus is 


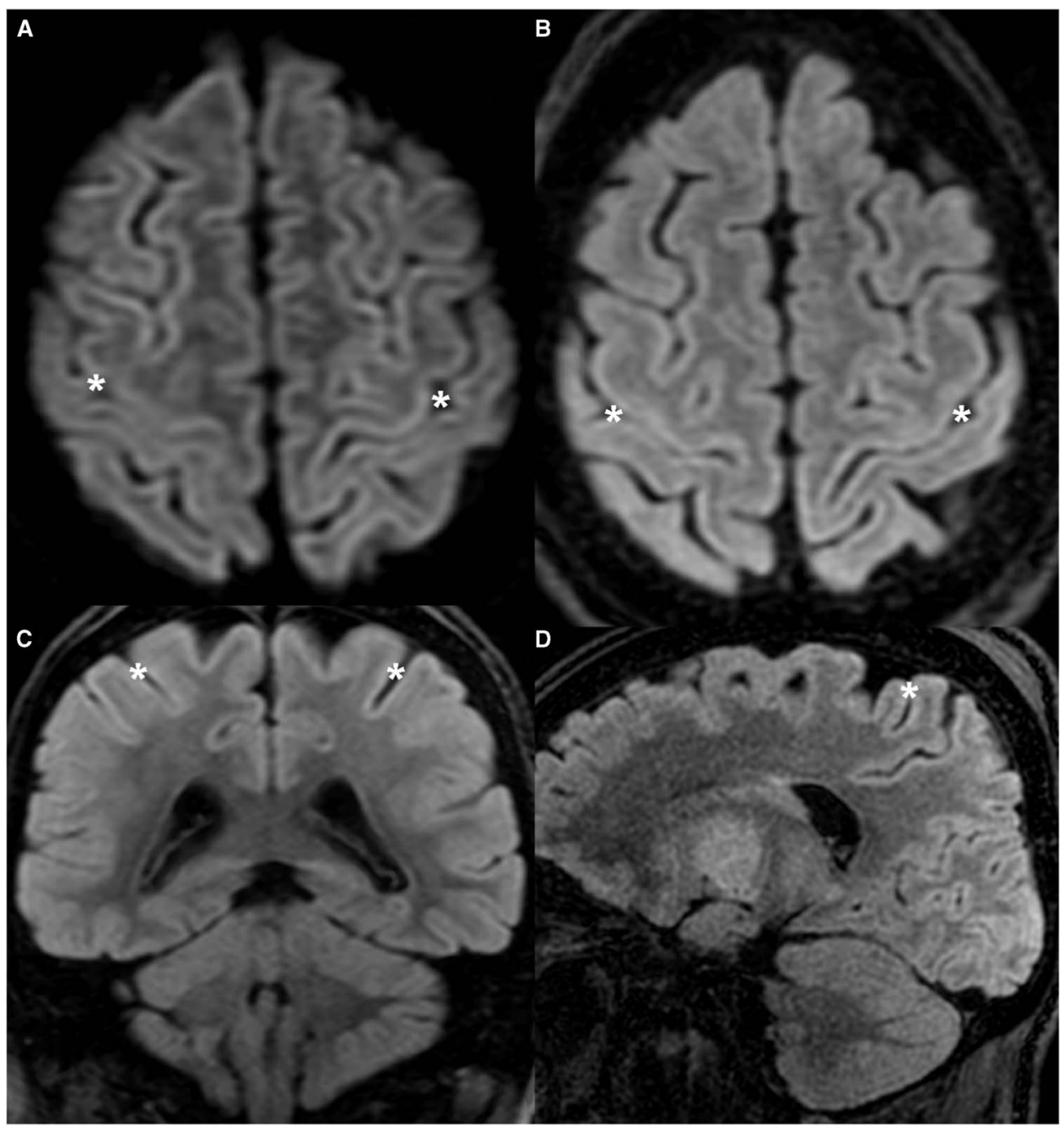

Figure 2: Tutorial patient with DCI (UCS 8) demonstrating the classic appearance of the UCS. (A) Axial DWI. $(B, C, D)$ Axial, coronal, and sagittal FLAIR images. Cortical thickness is fairly uniform throughout, including the anterior and posterior banks of the CS (asterisk). The abnormality is subtle and could be easily overlooked.

among the thinnest in the brain. ${ }^{1,5}$ In 1908, Brodman $^{14}$ reported mean cortical thickness measurements of 3.94 and $1.86 \mathrm{~mm}$ for motor and sensory cortices, respectively, based on autopsy specimens. Similar results were published in 1925 by von Economo and Koskinas. ${ }^{15}$ The central sulcus is the only sulcus in the brain with a difference in cortical thickness between the anterior and posterior banks this large. In 1996, Meyer ${ }^{5}$ found that cortical thickness measurements from T1-weighted images provided a method for locating the primary motor and primary somatosensory cortices. This study concluded that the difference in cortical thickness across the banks of the central sulcus is so pronounced that it can be readily localized by direct visual inspection. Another study ${ }^{8}$ showed that the signal intensity of the perirolandic cortex on FLAIR images is significantly lower than the cortex of the superior frontal cortex.

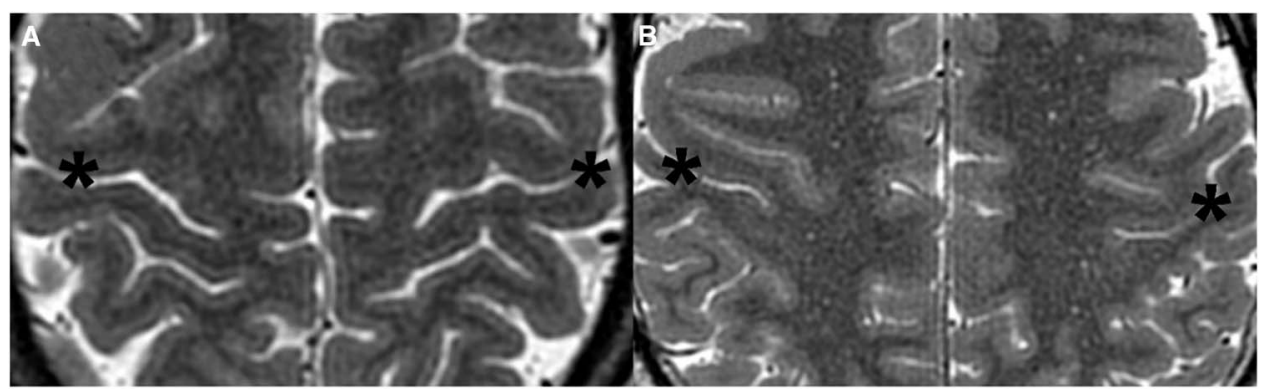

Figure 3: Cropped axial T2-weighted images demonstrating the TCS in representative control patients. (A) 54-year-old male (TCS 5). (B) 33-year-old male (TCS 7). Note the thin cortex along the posterior bank of the CS (asterisk) compared with the anterior bank of the CS and posterior banks of other adjacent sulci. 


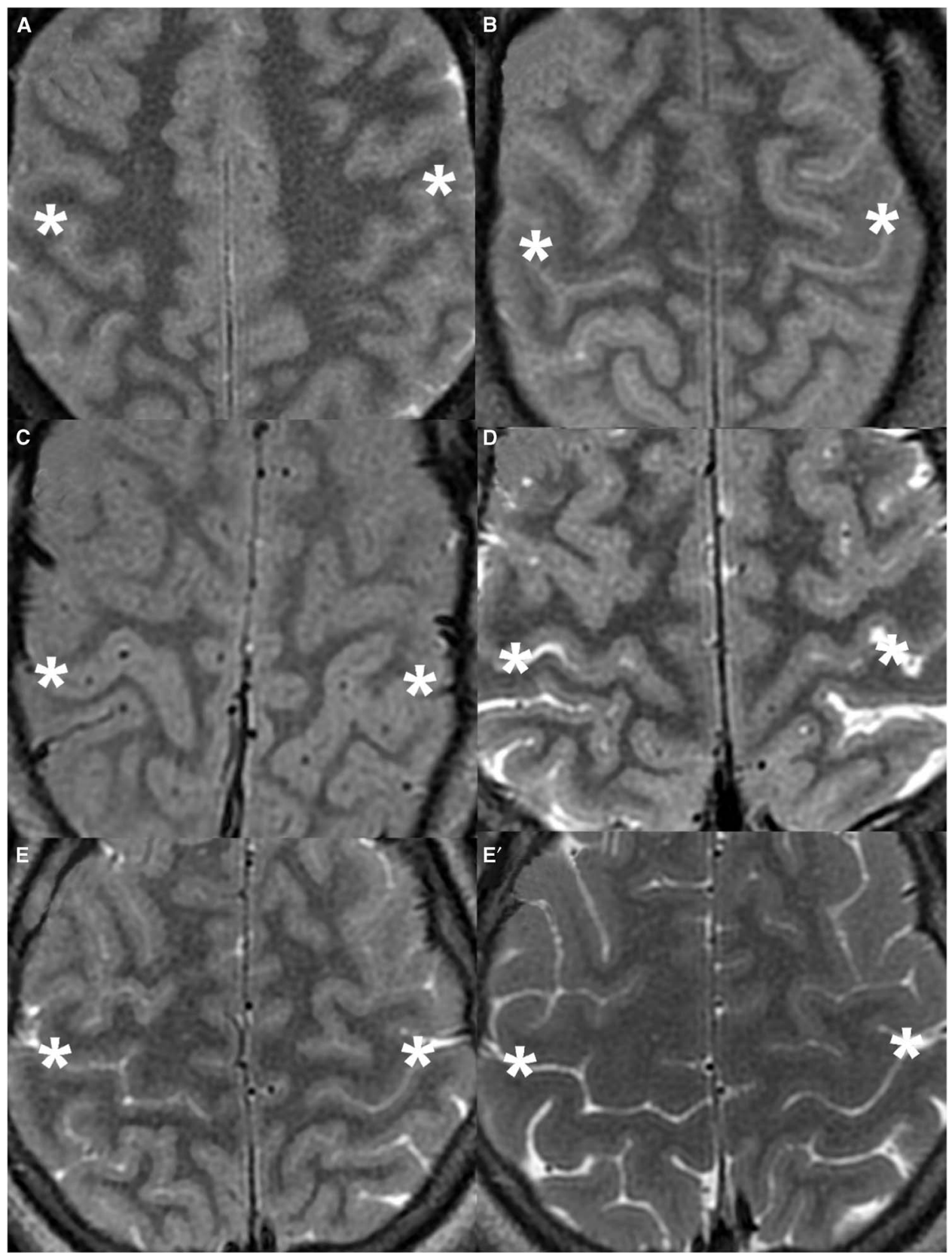

Figure 4: Cropped axial T2-weighted images demonstrating the UCS in representative DCI patients. (A) 55-year-old female (UCS 3). (B) 49-year-old female (UCS 6). (C) 18-year-old male (UCS 7). The cortical thickness of the posterior bank of the CS (asterisk) is uniform compared with the posterior banks of other sulci. All three readers detected the UCS in these patients. (D) 75-year-old male (UCS 4). The UCS is less apparent, where the medial cortex of the posterior bank of the CS is thicker than usual but the lateral cortex is fairly normal. Two of the three readers felt that the UCS was present in this patient. (E) 16-year-old male (UCS 2) during admission. (E') Patient UCS 2 after full recovery 3 months after admission. The UCS is difficult to appreciate on the initial exam. None of the readers felt that the UCS was present. When compared to the normal appearance on the follow-up exam, subtle diffuse cortical swelling and sulcal effacement are evident on the initial exam.

DCI often results from HIE. ${ }^{9}$ This is most commonly from cardiac or respiratory arrest. ${ }^{8}$ Other causes include hypoglycemia, overdose, toxins, strangulation, near drowning, status epilepticus, and electrocution. ${ }^{11}$ The clinical diagnosis of HIE is primarily made by history and physical examination, with imaging, EEG, and somatosensory-evoked potentials as supporting evidence. ${ }^{11}$ Previous studies ${ }^{9,12}$ describe cortical hyperintensity on DWI,
T2-weighted, and FLAIR images in patients with HIE. However, if the patient is imaged in the early subacute phase, the T2-weighted images may reveal only subtle abnormality. ${ }^{16,17}$ Conversely, a "supernormal" appearance can occur where T2 signal intensity in the cortex is increased and there is effacement of subarachnoid spaces presumably from cortical edema. ${ }^{18}$ In the second week, parenchymal T2 signal intensity can decrease. ${ }^{19}$ Diffuse cortical 
hyperintensity on FLAIR can also be seen with viral encephalitis, presumably from cortical injury. ${ }^{20}$

Our cases demonstrated this spectrum of MRI findings. While all readers identified the UCS in five patients, reader 2 felt that TCS was present in a cardiac arrest patient imaged at day 6 (UCS 4), and all readers regarded the day $7 \mathrm{MRI}$ of the patient with viral meningoencephalitis as normal (UCS 2). We postulate that the extent of cortical swelling is dependent on the degree of injury and timing of the exam. We suspect that UCS 2 and UCS 4 had relatively mild cortical swelling at the time of imaging, and hence only mild cortical thickening and signal change. While the UCS is particularly difficult to appreciate in UCS 2, some cortical swelling is appreciable when compared with the normal follow-up MRI acquired 3 months later (Figure 4G, $\mathrm{G}^{\prime}$ ). This case also shows that the UCS is potentially reversible.

\section{LIMITATIONS}

We acknowledge several limitations to this study. First, our study was small, comprising only seven DCI patients and seven CPs. We identified the DCI group based on MR findings. Patients with diffuse cortical injury but only subtle cortical thickening across the central sulcus may have been missed. Others with diffuse cortical injury were not included if UCS was absent. Our study group represents only a few of the causes of DCI. Future studies will be necessary to determine if the UCS is present in patients with such other causes as hypoglycemia, status epilepticus, and electrocution. For our normal population, we felt that the aneurysmscreening population would be least likely to have a brain abnormality to compromise TCS. That said, in our experience, the TCS is apparent in essentially all "normal" outpatient studies in our everyday work. Second, our results are not quantitative but based on subjective interpretation of the three neuroradiologists. This was purposeful, as qualitative evaluation is more readily employed in routine practice. Third, the presence of other topographic features to identify the central sulcus and other findings of brain injury were difficult to entirely conceal despite using selected images. However, given that the TCS and UCS are qualitative comparisons of cortical thickness across several adjacent gyri, small cutouts of just two or three gyri could not be used for testing.

\section{Conclusions}

In conclusion, our small study shows that the UCS can accurately identify DCI, especially in patients with HIE. The UCS can be subtle and easily overlooked, hence the reader must be vigilant for this finding. The accuracy of the UCS may depend on the extent of cortical injury and time from onset of injury. Also, the UCS may be reversible, as seen in our case of viral meningoencephalitis.

\section{DisClosures}

Andrew Leung, Apurva Patel, Basem Bahakeem, David Pelz, Donald Lee, and Manas Sharma declare that they have nothing to disclose.

\section{REFERENCES}

1. Naidich TP, Tang CY, Ng JC, Delman BN. Surface anatomy of the cerebrum. In: Naidich TP, Castillo $M$, Cha $S$, Smirniotopoulos JG editors. Imaging of the Brain. Expert Radiology Series. Philadelphia: Elsevier Health Sciences; 2012: P. 149-51.

2. Kido DK, LeMay M, Levinson AW, Benson WE. Computed tomographic localization of the precentral gyrus. Radiology. 1980;135(2):373-7.

3. Iwasaki S, Nakagawa H, Fukusumi A, et al. Identification of pre- and postcentral gyri on CT and MRI images on the basis of the medullary pattern of the cerebral white matter. Radiology. 1991;179(1):207-13.

4. Wagner M, Jurcoane A, Hattingen E. The U sign: tenth landmark to the central region on brain surface reformatted MR imaging. AJNR Am J Neuroradiol. 2013;34(2):323-6.

5. Meyer JR, Roychowdhury S, Russell EJ, Callahan C, Gitelman D, Mesulam MM. Location of the central sulcus via cortical thickness of the precentral and postcentral gyri on MR. AJNR Am J Neuroradiol. 1996;17(9):1699-706.

6. Biega TJ, Lonser RR, Butman JA. Differential cortical thickness across the central sulcus: a method for identifying the central sulcus in the presence of mass effect and vasogenic edema. AJNR Am J Neuroradiol. 2006;27(7):1450-3.

7. Togao O, Yoshiura T, Mihara F, et al. Cortical thickness difference across the central sulcus visualized in the presence of vasogenic edema. Eur J Radiol. 2006;66(2):274-81.

8. Karaarslan E, Arslan A. Perirolandic cortex of the normal brain: low signal intensity on turbo FLAIR MR images. Radiology. 2003;227(2):538-41.

9. McKinney AM, Teksam M, Felice R, et al. Diffusion-weighted imaging in the setting of diffuse cortical laminar necrosis and hypoxic-ischemic encephalopathy. AJNR Am J Neuroradiol. 2004;25(10):1659-65.

10. Hossmann KA, Joehn-Berlage M. Diffusion and perfusion MR imaging of cerebral ischemia. Cerbrovasc Brain Metab Rev. 1995;7(3):187-217.

11. Commichau C. Hypoxic-ischemic encephalopathy. In: Noseworthy $\mathbf{J}$ editor. Neurological Therapeutics: Principles and Practice. New York: Martin Dunitz; 2003: P. 470-80.

12. Siskas N, Lefkopoulos A, Ioannidis I, Charitandi A, Dimitriadis AS. Cortical laminar necrosis in brain infarcts: serial MRI. Neuroradiology. 2003;45(5):282-8.

13. Randolph JJ. Online Kappa Calculator [software]; 2008. Available at: http://justus.randolph.name/kappa.

14. Brodman K. Über Rindenmessungen. Zentralbl Nervenheilk Psychiatrie. 1908;19:781-98.

15. von Economo C, Koskinas GN. Die Cytoarchitektonik der Himrinde des Erwachsenen Menschen. Berlin: Springer-Verlag; 1925.

16. Arbalaez A, Castillo M, Mukherji SK. Diffusion-weighted MR. imaging of global cerebral anoxia. AJNR Am J Neuroradiol. 1999;20(6):999-1007.

17. Kawahara H, Takeda Y, Tanaka A, et al. Does diffusion-weighted magnetic resonance imaging enable detection of early ischemic change following transient cerebral ischemia? J Neurol Sci. 2000;181(12):73-81.

18. Lee DH, Nathanson JA, Fox AJ, Pelz DM, Lownie SP. Magnetic resonance imaging of brain death. Can Assoc Radiol J. 1995; 46(3):174-8.

19. Lansberg MG, Thijs VN, O'Brien MW, et al. Evolution of apparent diffusion coefficient, diffusion-weighted, and t2-weighted signal intensity of acute stroke. AJNR Am J Neuroradiol. 2001; 22(4):637-44.

20. Lee JH, Na DG, Choi KH, et al. Subcortical low intensity on MR images of meningitis, viral encephalitis, and leptomeningeal metastasis. AJNR Am J Neuroradiol. 2002;23(4):535-42. 